\title{
Theoretical Substituent Electrophilicities
}

\author{
Marcos Caroli Rezende ${ }^{*, a}$ and Daniela Millán ${ }^{b}$ \\ ${ }^{a}$ Facultad de Química y Biología, Universidad de Santiago, Av. Bernardo O'Higgins 3363, Santiago, Chile \\ ${ }^{b}$ Facultad de Química, Pontificia Universidad Católica de Chile, Av. Vicuña Mackenna 4860, Santiago, Chile
}

\begin{abstract}
Uma equação de tipo Hammett, relacionando as eletrofilicidades teóricas globais e de substituinte, foi derivada para etilenos e ácidos benzóicos substituídos, permitindo o cálculo de constantes eletrofílicas para substituintes $\sigma_{\omega}$. As constantes teóricas foram correlacionadas com parâmetros cinéticos ou termodinâmicos para vários processos químicos da literatura. Embora formalmente semelhantes às constantes de Hammett, as constantes eletrofílicas para substituintes são obtidas a partir de postulados teóricos inteiramente distintos. As semelhanças e diferenças entre os dois conjuntos de constantes são discutidas e racionalizadas em termos da definição do poder eletrofílico de uma espécie química.
\end{abstract}

A Hammett-like equation, relating theoretical global and substituent electrophilicities, is derived for substituted ethylenes and benzoic acids, allowing the calculation of electrophilic substituent constants $\sigma_{\omega}$. Correlations are given between the theoretical $\sigma_{\omega}$ constants and kinetic or thermodynamic parameters of various chemical processes from the literature. Though electrophilic substituent constants are formally similar to the Hammett constants, they are derived from entirely different theoretical postulates. The similarities and differences between the two sets of constants are discussed and rationalized in terms of the definition of the electrophilic power of a chemical species.

Keywords: substituent electrophilicity, electrophilicity index, Hammett equation, sigma constants

\section{Introduction}

Empirical linear-free-energy relationships have been invaluable in the investigation of structural properties and reactivities of organic compounds in solution. Among them, the Hammett relationship has been permanently utilized in the interpretation of reaction mechanisms, and in the rationalization of the influence of substituents on the fate of a wide variety of reactions. The fact that the constants derived from these equations were empirical led to efforts to look for correlations between them and other theoretically derived parameters, which might be obtained from quantum-chemical calculations. Several indices derived from density functional theory (DFT) have been increasingly employed in the interpretation of organic reactivity. They include parameters like chemical potential, hardness, softness and electrophilicity indices.

Efforts to associate substituent effects with such indices have yielded variable results. The group electronegativity,

\footnotetext{
*e-mail: marcos.caroli@usach.cl
}

hardness and softness of 30 organic groups were calculated within the framework of density functional theory, with satisfactory results in comparison with experimental data. ${ }^{1}$

A Hammett-like equation was reported for the chemical hardness or the HOMO-LUMO (highest occupied molecular orbital and lowest unoccupied molecular orbital, respectively) gap of a number of molecules, leading to the proposal of hardness substituent constants, similar to the Hammett's $\sigma$ values. $^{2}$

The reactivity and stability of particular classes of compounds were explained in terms of local and global density functional theory-based reactivity descriptors. ${ }^{3}$

Intrinsic electronic contributions to the Hammett's $\sigma_{\mathrm{p}}$ constants were described for a series of 42 functional groups, yielding constants $\sigma_{\mathrm{e}}(\omega)$, based on electrophilicity indices. ${ }^{4} \mathrm{~A}$ reasonably linear dependence between Hammett's $\sigma_{p}$ constants and the electrophilicities of a series of substituted benzoic acids was reported by Elango et al. ${ }^{5}$

Since then, electrophilicity indices have proved to be increasingly useful in the interpretation of a variety of thermodynamic and kinetic processes. ${ }^{6}$ They constitute 
one example of what has been recently termed philicity descriptors. Recalling the original approach by Hammett, the prediction of $\mathrm{pKa}$ values has been suggested using group philicities.?

A more systematic study in the same line has been published recently, in which correlations were sought between the acidity of meta- and para-substituted aromatic acids and DFT-derived indices. ${ }^{8}$ Theoretical descriptors included free-energy deprotonation energies, electronegativies $(\chi)$, hardness $(\eta)$ and electrophilicitybased charge-transfer (ECT) indices and correlations were often poor.

In a study of a set of substituted ethylenes, Domingo et al. ${ }^{4}$ obtained a good correlation between Hammett's $\sigma_{p}$ constants and the logarithm of their calculated global electrophilicities $(\omega)$, allowing them to define what they termed "the intrinsic electronic contributions to the Hammett substituent constants".

In the present communication, we applied the same method to a set of substituted benzoic acids, showing that the results described by the authors constitute a particular case of a more general behavior, with a much wider scope. In consequence, a Hammett-like equation was here defined as an equation that relates the global electrophilicity of substituted benzoic acids with their substituent electrophilicities. The treatment allowed us to define a set of electrophilic substituent constants $\left(\sigma_{\omega}\right)$ that are shown to apply to various systems.

\section{Methodology}

All calculations were performed with the Gaussian 03 package. ${ }^{9}$ The structures of all substituted benzoic acids were optimized employing the hybrid B3LYP/6-31G* or, for the purpose of comparison, the semiempirical AM1 method. The chemical potential $\mu \approx\left(\varepsilon_{\mathrm{H}}+\varepsilon_{\mathrm{L}}\right) / 2$ and molecular hardness $\eta \approx \varepsilon_{\mathrm{H}}-\varepsilon_{\mathrm{L}}$ for each structure were obtained from the HOMO and LUMO energies, $\varepsilon_{\mathrm{H}}$ and $\varepsilon_{\mathrm{L}}$, respectively. The global electrophilicities $(\omega)$ were calculated with the aid of the relationship $\omega=\mu^{2} / 2 \eta$. The electrophilic substituent constants $\left(\sigma_{\omega}\right)$ were derived from the global electrophilicities of the substituted benzoic acids as $\sigma_{\omega}=\log \left(\omega_{X} / \omega_{H}\right)$, where the subscripts refer to substituents $\mathrm{X}$ and $\mathrm{H}$, respectively.

\section{Results and Discussion}

The global electrophilicity index $(\omega)$ measures the stabilization in energy when a molecule acquires an additional electronic charge from the environment. The index is given by the following simple equation 1 in terms of the electronic chemical potential $(\mu)$ and the chemical hardness $(\eta)$.

$\omega=\mu^{2} / 2 \eta$

Both quantities are obtained from one-electron energies of the frontier molecular orbital HOMO and LUMO, $\varepsilon_{\mathrm{H}}$ and $\varepsilon_{\mathrm{L}}$, as $\mu \approx\left(\varepsilon_{\mathrm{H}}+\varepsilon_{\mathrm{L}}\right) / 2$ and $\eta \approx\left(\varepsilon_{\mathrm{H}}-\varepsilon_{\mathrm{L}}\right)$, respectively. ${ }^{10}$

The electrophilicity index takes into account both the propensity of the molecule to acquire an additional electronic charge, and the resistance of the system to exchange charge with the environment.

\section{Protocol for the derivation of the constant}

Our analysis started from a comparison of the experimental $\sigma$ values tabulated by Hansch et al. ${ }^{11}$ and the global electrophilicity index $(\omega)$, evaluated for a set of substituted benzoic acids. The protocol adopted by Domingo $e t$ al. ${ }^{4}$ was closely followed by us for substituted ethylenes, arriving, however, at conclusions of a much wider scope.

Twenty three representative meta- and para-substituents commonly present in organic compounds (Table 1) were selected. Our list included aliphatic and aromatic, charged and uncharged substituents, with $\sigma$ values ranging from -0.83 , for strong electron-donors such as $\mathrm{NMe}_{2}$, to +1.00 , for strong electron-withdrawing groups, such as $\mathrm{Me}_{2} \mathrm{~S}^{+}$. The $\omega$ values for the corresponding substituted benzoic acids were calculated at the HF/6-31G* level of theory, using the Gaussian03 package. ${ }^{9}$

The linear correlation between the calculated $\omega$ values for all substituted acids and the corresponding $\sigma$ constants was rather poor $\left(R^{2}=0.52\right)$. Nevertheless, it was practically the same as that reported by Domingo et al. ${ }^{4}\left(\mathrm{R}^{2}=0.53\right)$ for a similar plot of their set of 42 substituted ethylenes. The authors obtained a better correlation $\left(R^{2}=0.84\right)$ when, instead of looking for a linear dependence of $\sigma_{p}$ on $\omega$, they employed a logarithmic relationship. ${ }^{4}$ In our case, the same procedure also improved our correlation $\left(R^{2}=0.74\right)$, when a dependence of $\sigma$ on $\log \omega$ was assumed.

After selecting only 20 functional groups from their set of substituted ethylenes, Domingo et al. ${ }^{4}$ proposed equation 2, with an excellent correlation $\left(R^{2}=0.99, n=20\right)$.

$\sigma_{\mathrm{e}}(\omega)=1.43 \log \omega-0.20$

Equation 2 allowed the definition of a set of electrophilic constants $\sigma_{\mathrm{e}}(\omega)$, which the authors described as "the intrinsic electronic contribution to Hammett's constants". ${ }^{4}$

What the authors apparently overlooked, after recognizing a linear dependence between Hammett's $\sigma_{\mathrm{p}}$ and 
Table 1. Hammett's $\sigma_{\mathrm{p}}$ and $\sigma_{\mathrm{m}}$ constants (global electrophilicities $\omega_{\mathrm{p}}$ and $\omega_{\mathrm{m}}$ for para- and meta-substituted benzoic acids $\mathrm{X}-\mathrm{C}_{6} \mathrm{H}_{4}$-COOH, respectively) and calculated substituent electrophilic constants $\sigma_{\omega}{ }^{\mathrm{p}}$ and $\sigma_{\omega}{ }^{\mathrm{m}}$

\begin{tabular}{|c|c|c|c|c|c|c|c|c|}
\hline Compounds & $\mathrm{X}$ & $\sigma_{p}{ }^{a}$ & $\sigma_{\mathrm{m}}{ }^{\mathrm{a}}$ & $\omega_{\mathrm{p}} / \mathrm{eV}$ & $\omega_{\mathrm{m}} / \mathrm{eV}$ & $\sigma_{\omega}^{p ~ b}$ & $\sigma_{\omega}^{\mathrm{mc}}$ & $\sigma_{e}(\omega)^{d}$ \\
\hline 1 & $\mathrm{NMe}_{2}$ & -0.83 & -0.16 & 0.27 & 0.39 & -0.28 & -0.12 & -0.61 \\
\hline 2 & $\mathrm{NH}_{2}$ & -0.66 & -0.16 & 0.28 & 0.39 & -0.27 & -0.12 & -0.55 \\
\hline 3 & $\mathrm{OH}$ & -0.37 & 0.12 & 0.41 & 0.47 & -0.10 & -0.04 & -0.31 \\
\hline 4 & $\mathrm{OMe}$ & -0.27 & 0.12 & 0.40 & 0.44 & -0.11 & -0.07 & -0.34 \\
\hline 5 & t-butyl & -0.2 & -0.1 & 0.48 & 0.57 & -0.03 & 0.04 & - \\
\hline 6 & $\mathrm{Me}$ & -0.17 & -0.07 & 0.48 & 0.49 & -0.03 & -0.03 & -0.12 \\
\hline 7 & cyclohexyl & -0.15 & -0.05 & 0.47 & 0.46 & -0.04 & -0.05 & - \\
\hline 8 & 3-thienyl & -0.02 & 0.03 & 0.51 & 0.46 & -0.01 & -0.05 & - \\
\hline 9 & phenyl & -0.01 & 0.06 & 0.54 & 0.45 & 0.02 & -0.06 & 0.28 \\
\hline 10 & $\mathrm{H}$ & 0.00 & 0.00 & 0.52 & 0.52 & 0.00 & 0.00 & 0.00 \\
\hline 11 & $\mathrm{SMe}$ & 0.00 & 0.15 & 0.62 & 0.57 & 0.08 & 0.04 & 0.13 \\
\hline 12 & 2-furyl & 0.02 & 0.06 & 0.49 & 0.41 & -0.03 & -0.10 & - \\
\hline 13 & $\mathrm{Cl}$ & 0.23 & 0.37 & 0.61 & 0.61 & 0.07 & 0.07 & 0.14 \\
\hline 14 & 4-pyridyl & 0.44 & 0.27 & 0.65 & 0.58 & 0.10 & 0.05 & - \\
\hline 15 & $\mathrm{Br}$ & 0.48 & 0.32 & 0.61 & 0.54 & 0.07 & 0.02 & 0.13 \\
\hline 16 & 3-pyridazinyl & 0.48 & 0.28 & 0.82 & 0.70 & 0.20 & 0.13 & - \\
\hline 17 & $\mathrm{CN}$ & 0.66 & 0.56 & 0.87 & 0.76 & 0.22 & 0.16 & 0.54 \\
\hline 18 & $\mathrm{Me}_{3} \mathrm{P}^{+}$ & 0.74 & 0.73 & 2.48 & 2.29 & 0.67 & 0.64 & 1.25 \\
\hline 19 & $\mathrm{EtSO}_{2}$ & 0.77 & 0.66 & 0.83 & 0.76 & 0.20 & 0.16 & - \\
\hline 20 & $\mathrm{NO}_{2}$ & 0.78 & 0.71 & 1.01 & 0.92 & 0.29 & 0.25 & 0.79 \\
\hline 21 & $\mathrm{Me}_{3} \mathrm{~N}^{+}$ & 0.82 & 0.88 & 2.28 & 2.26 & 0.64 & 0.64 & 1.20 \\
\hline 22 & $\mathrm{Me}_{2} \mathrm{~S}^{+}$ & 0.90 & 1.00 & 2.68 & 2.56 & 0.71 & 0.69 & 1.31 \\
\hline 23 & $\mathrm{CF}_{3} \mathrm{SO}_{2}$ & 0.96 & 0.83 & 1.01 & 0.91 & 0.29 & 0.24 & - \\
\hline
\end{tabular}

${ }^{a}$ Values from reference 10 ; ${ }^{\mathrm{b}}$ calculated as $\log \left(\omega_{\mathrm{p}} / \omega_{\mathrm{H}}\right)$; ${ }^{\mathrm{c}}$ calculated as $\log \left(\omega_{\mathrm{m}} / \omega_{\mathrm{H}}\right)$; ${ }^{\mathrm{d}}$ values of electrophilicity indices from reference 4.

their $\log \omega$ values, was that such a good correlation was an indication that a Hammett-like relationship should exist for the global electrophilicity $(\omega)$ of any family of substituted compounds.

Equation 3 for substituted ethylenes or benzoic acids may be indeed written as,

$\log \left(\omega / \omega_{H}\right)=\rho_{\omega} \sigma_{\omega}$

where all global electrophilicities of a family of substituted compounds are expressed in terms of a constant substituent contribution $\sigma_{\omega}$ and a parameter $\rho_{\omega}$ that should vary with the analyzed system. It is easy to see that simple manipulation of equation 3 leads to equation 2 , if $\omega_{\mathrm{H}}=0.73 \mathrm{eV}^{4}$ and $\rho_{\omega}=0.7$.

Following the historical choice of Hammett of substituted benzoic acids as the basis of his original $\sigma$ values, $\rho_{\omega}=1$ was arbitrarily assumed for our set, and values for the $\sigma_{\omega}$ substituent constants are immediately obtained from equation 3 . These values are given in
Table 1 , as $\sigma_{\omega}{ }^{\mathrm{p}}$ and $\sigma_{\omega}{ }^{\mathrm{m}}$ for the para- and meta-substituent electrophilicity constants.

A plot of the $\sigma_{\mathrm{e}}(\omega)$ values, reported by Domingo et al. ${ }^{4}$ for substituted ethylenes, $v s$. the $\sigma_{\omega}{ }^{p}$ obtained in this work is shown in Figure 1. The obtained straight line corresponds to the relationship $\sigma_{\mathrm{e}}(\omega)=1.97 \sigma_{\omega}{ }^{\mathrm{p}}$, allowing the calculation of $\sigma_{\omega}{ }^{p}$ values for other substituents from the reported $\sigma_{e}(\omega)$ values. ${ }^{4}$ The linear correlation is very good $\left(\mathrm{R}^{2}=0.97\right)$. The slope of the observed linear plot gives the value of $\rho_{\omega}$ for that family of compounds, assuming the family of substituted benzoic acids as a reference. The value of $\rho_{\omega}$ measures how susceptible is the global electrophilicity of a given family of substituted compounds to the substituent electrophilicity.

The slope of 1.97 in the plot of Figure 1 indicates that the global electrophilicities of substituted ethylenes depend more heavily on the substituent electrophilicities than those of the corresponding substituted benzoic acids.

The good correlation obtained for the electrophilic $\sigma$ values of Figure 1 is not accidental, and is not due to the 


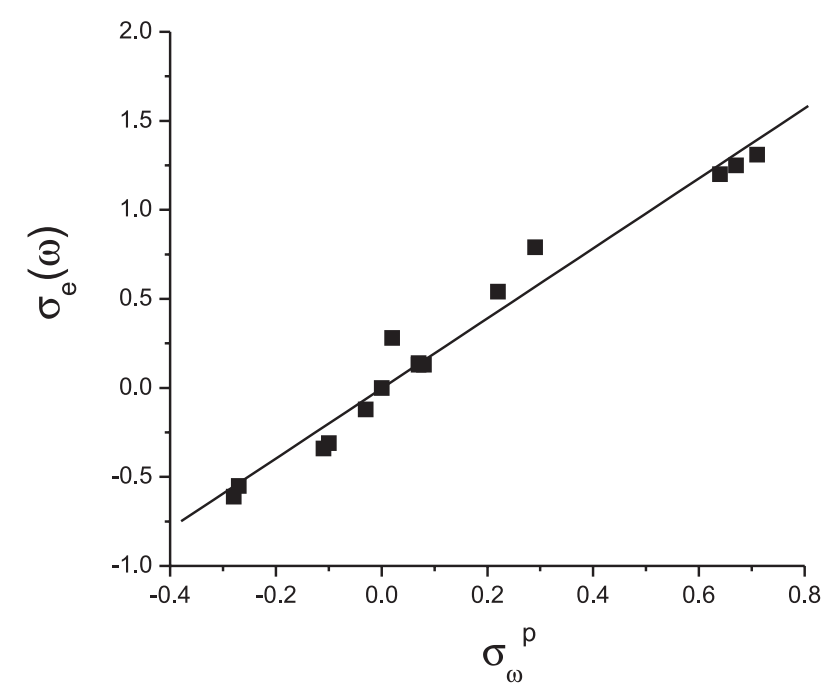

Figure 1. Plot of the electrophilicity index $\sigma_{\mathrm{e}}(\omega)$ calculated from substituted ethylenes ${ }^{4}$ vs. $\sigma_{\omega}{ }^{\mathrm{p}}$ values (this work) (correlation $\mathrm{R}^{2}=0.97$ ).

particular level of calculation employed. Table 2 lists the global electrophilicities of a number of substituted benzoic acids, which were calculated with the aid of equation 1 , but at a lower level of theory, the semiempirical AM1 method. Many of the substituents of Table 2 were not included in Table 1, and were chosen so, as to span a reasonably wide range of the $\sigma_{\mathrm{e}}(\omega)$ values reported in the literature, ${ }^{4}$ which were calculated with the B3LYP/6-31G* method.

A comparison of the values calculated with the B3LYP/6-31G* method of Table 1 with those with the AM1 of Table 2 shows that, although the electrophilic $\sigma$ constants differ in their absolute values, substituent trends are conserved. In spite of the different methods employed and the different families of substituted electrophiles, a

Table 2. Values of the electrophilicity index $\sigma_{\mathrm{e}}(\omega)$ for various substituents and of the logarithm of electrophilicity ratios of substituted benzoic acids $\log \left(\omega / \omega_{\mathrm{H}}\right)$ calculated with the AM1 method

\begin{tabular}{lcc}
\hline para-substituents & $\sigma_{\mathrm{e}}(\omega)$ values $^{\mathrm{a}}$ & $\log \left(\omega / \omega_{\mathrm{H}}\right)^{\mathrm{b}}$ \\
\hline $\mathrm{H}$ & 0 & 0 \\
$\mathrm{CBr}_{3}$ & 0.62 & 0.098 \\
$\mathrm{CHO}$ & 0.57 & 0.092 \\
$\mathrm{COMe}$ & 0.51 & 0.086 \\
$\mathrm{SiH}_{3}$ & 0.38 & 0.027 \\
$\mathrm{Et}$ & -0.14 & -0.01 \\
$\mathrm{OH}$ & -0.31 & -0.016 \\
$\mathrm{NH}_{2}$ & -0.55 & -0.077 \\
$\mathrm{OMe}$ & -0.34 & -0.032 \\
$\mathrm{NMe}_{2}$ & -0.61 & -0.099 \\
\hline
\end{tabular}

${ }^{a}$ From reference 4 , calculated for substituted ethylenes with the B3LYP/6-31G* method; ' calculated for substituted benzoic acids with the AM1 method. reasonably good correlation $\left(R^{2}=0.95\right)$ is still obtained between $\log \left(\omega / \omega_{\mathrm{H}}\right)$ (calculated with the AM1 method) and $\sigma_{\mathrm{e}}(\omega)$ (calculated with the hybrid DFT method) as can be seen in Figure 2 (where the data of Table 2 are plotted).

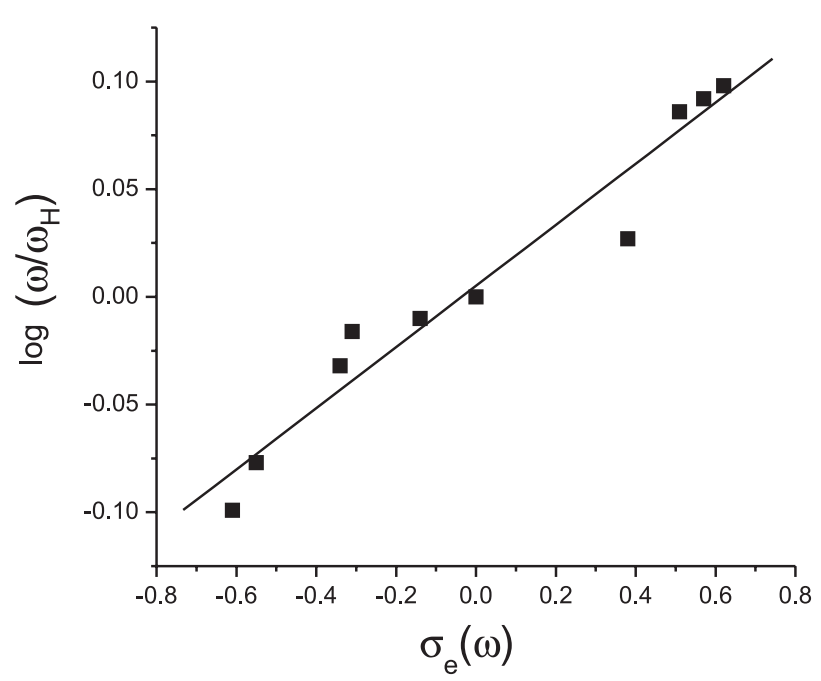

Figure 2. Plot of the logarithm of the global electrophilicity ratios of substituted benzoic acids (calculated by the AM1 method) vs. the electrophilicity index $\sigma_{e}(\omega),{ }^{4}$ calculated from substituted ethylenes with the B3LYP/6-31G* level.

Thus, the original definition of the $\sigma_{\mathrm{e}}(\omega)$ parameter, by Domingo et al. ${ }^{4}$ as "the intrinsic electronic contribution to the Hammett substituent constant" is not entirely correct. This contribution should be constant, independent of the system under consideration, which is not the case. Values for the $\sigma_{\omega}$ constant obtained in this work are very different from those previously reported, yet they are as "intrinsic" as the latter.

The most important is not their absolute values, but the fact (shown in Figure 1) that they are proportional, and that this proportionality is measured in terms of a Hammett-like $\rho_{\omega}$ factor that is characteristic of the system under study.

So, the above definition must be correct, and the $\sigma_{\omega}{ }^{p}$ parameter must not be regarded as an electronic contribution to Hammett's $\sigma_{\mathrm{p}}$, but as an electrophilic substituent constant in its own right. Positive values of $\sigma_{\omega}$ correspond to substituents that are more electrophilic than $\mathrm{H}$, negative values to substituents that act as nucleophilic groups, or as electron-donors. These trends parallel those of the experimentally derived Hammett's $\sigma$ constants. Interestingly, the electrophilic constants obtained from substituted benzoic acids allow a distinction to be made between the electrophilicities of meta- and para-substituents. Inspection of Table 1 shows that the substituent contribution to the global electrophilicity of benzoic acids is generally larger for para-substituents than for the meta-analogs. 
Our contention that a Hammett-like relationship between global and substituent electrophilicities should exist for a large variety of systems may be verified by comparison with data from the literature. If the electrophilic $\sigma_{\omega}$ values are constants that are characteristic of the group and its position in a substituted system, they should yield good correlations in various Hammett-like plots.

\section{Applications to data from the literature}

\section{Correlation with basicity and acidity values}

Although the electrophilic constants $\sigma_{\omega}$ (unlike the original Hammett's $\sigma$ values) were derived from purely theoretical considerations, a first test of their validity would be the existence of good correlations with the basicity or the acidity of organic compounds. The dependence of the basicity of 15 substituted pyridines ${ }^{12,13}$ on the electrophilicity of their substituents is illustrated in Figure 3. A good correlation between the pKa values of the protonated pyridines $v s . \sigma_{\omega}$ and a $\rho_{\omega}$ value of -16.0 indicate that the basicity of pyridines decreases significantly with the substituent electrophilicity.

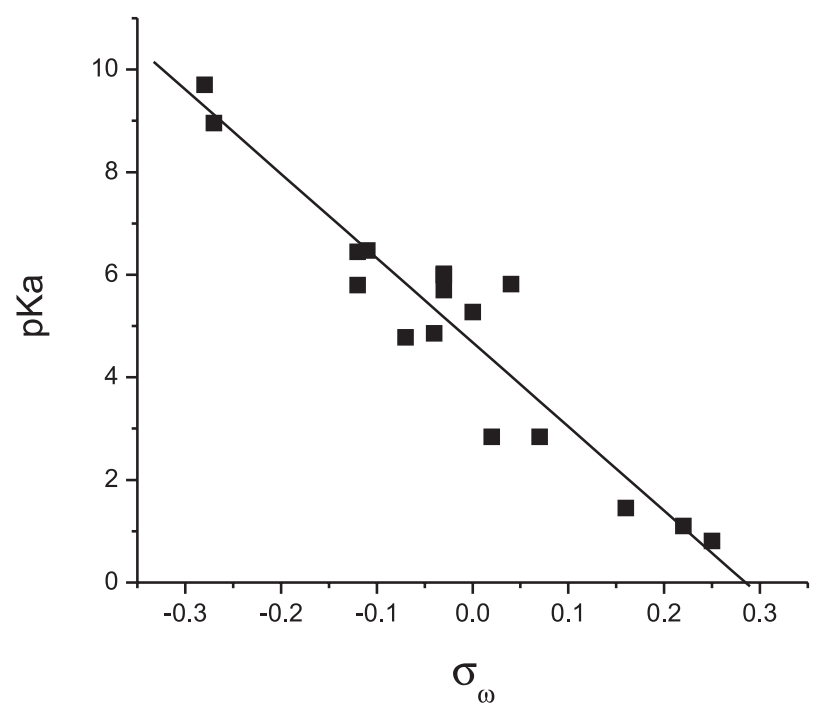

Figure 3. Plot of pKa values of 3- and 4-substituted pyridinium in water $v s$. the corresponding substituent electrophilic $\sigma_{\omega}$ values (correlation $\mathrm{R}^{2}=0.89$ ). $\mathrm{pKa}$ values were obtained from references 12 and 13 .

Figure 4 is a plot of the pKa of protonated pyridine N-oxides ${ }^{14,15}$ vs. $\sigma_{\omega}$ values. The smaller $\rho_{\omega}$ value of -9.6 reflects the decreased importance of the substituent electrophilicity to the basicity of this system, when compared with that of pyridines.

A plot of the pKa of 28 mono- and di-substituted phenols ${ }^{16} v s . \sigma_{\omega}$ values is shown in Figure 5. A reasonable linearity is obtained, with a $\rho_{\omega}$ value of -5.0 . Note that the two data points that correspond to charged substituents (3- and $4-\mathrm{Me}_{3} \mathrm{~N}^{+}$) fall significantly off the regression

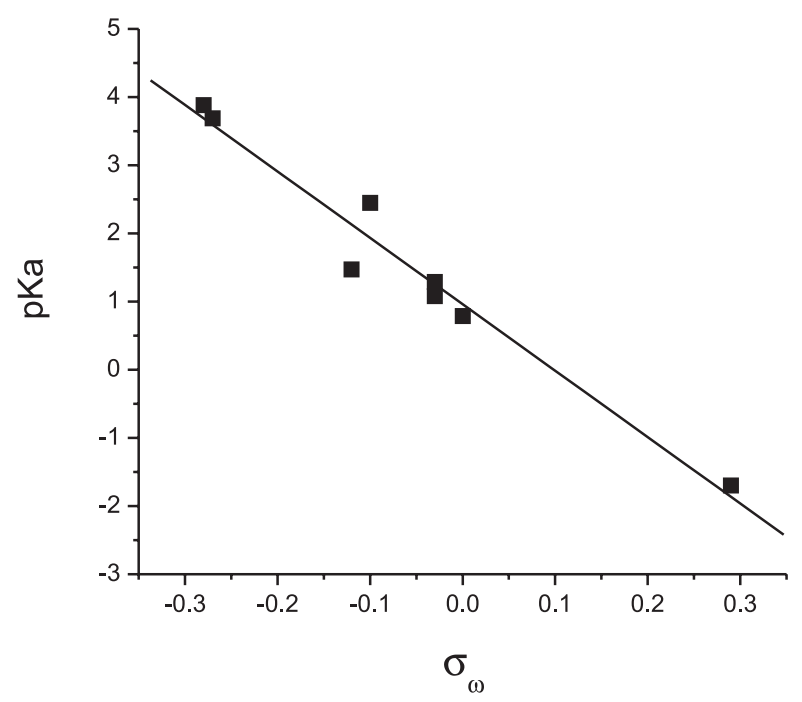

Figure 4. Plot of pKa values of protonated pyridine $\mathrm{N}$-oxides $v s$. the corresponding substituent electrophilic $\sigma_{\omega}$ values (correlation $\mathrm{R}^{2}=0.96$ ). pKa values were obtained from reference 14 and 15 .

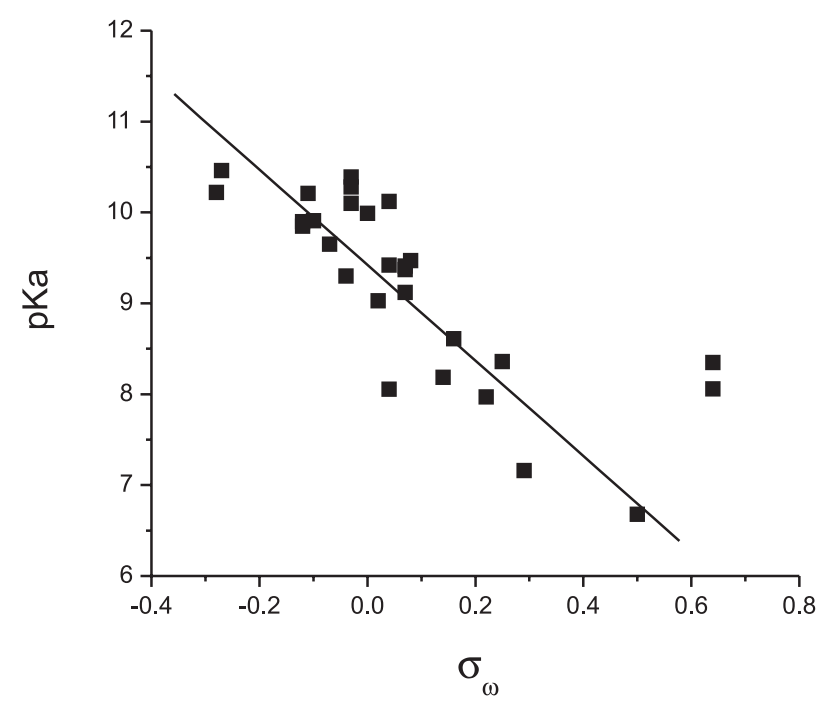

Figure 5. Plot of the pKa values of 3- and 4- mono- and di-substituted phenols $v s$. the corresponding substituent electrophilic $\sigma_{\omega}$ values (correlation $\mathrm{R}^{2}=0.76$ ). $\mathrm{pKa}$ values were obtained from reference 16 . The two points with $\sigma_{\omega}=0.64$ correspond to the 3 - and $4-\mathrm{Me}_{3} \mathrm{~N}^{+}$substituents.

straight line. The electrophilic contribution of these substituents to the acidity of the series of phenols is overestimated, according to the plot. As discussed below (Figure 8), the contribution of charged substituents to the global electrophilicity of benzoic acids is exaggerated, when compared to their contribution to the acidity of the same compounds, estimated by Hammett's $\sigma$ values.

\section{Correlation with an experimental electrophilicity parameter}

Equation 4 was proposed by Mayr and Patz ${ }^{17}$ to describe the variation of the reaction rates $k$ for a variety of nucleophile/electrophile pairs. 
$\log \mathrm{k}\left(20^{\circ} \mathrm{C}\right)=\mathrm{s}(N+E)$

where $N$ and $E$ are parameters that are characteristic of a particular nucleophile or electrophile, respectively. For a series of analogous electrophiles reacting with the same nucleophile, the s and $N$ parameters are constant and equation 4 assumes the familiar form of Hammett's relationship. Accordingly, a linear relationship would be anticipated here between the experimental electrophilicity value $E$ and the electrophilic constants $\sigma_{\omega}$.

A plot of the electrophilicity parameter $E$ of diarylcarbenium ions ${ }^{18} v s$. the sum of the $\sigma_{\omega}{ }^{\mathrm{p}}$ values of the corresponding substituents is shown in Figure 6.<smiles>[X]c1ccc(Cc2ccc([X])cc2)cc1</smiles>

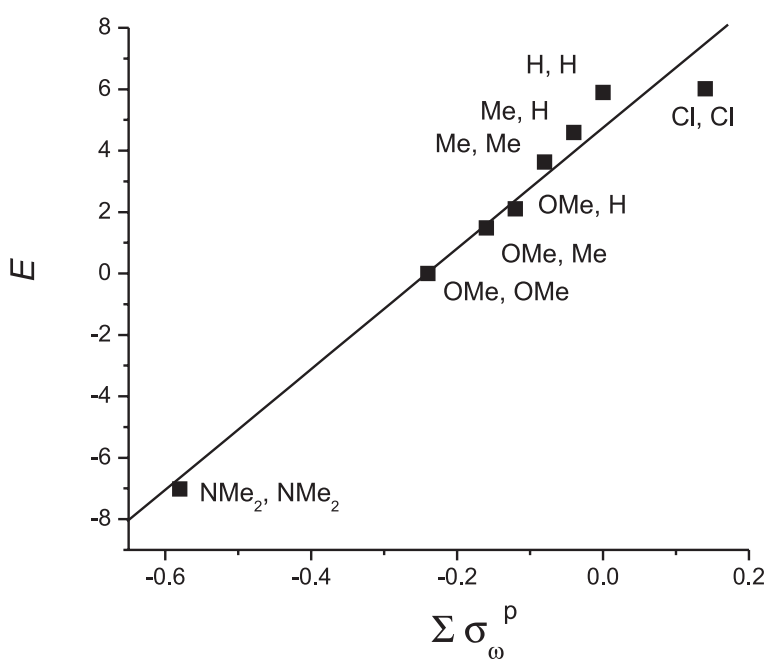

Figure 6. Plot of the electrophilicity $E$ of diarylcarbenium ions $\operatorname{ArAr}^{\prime} \mathrm{CH}^{+} v s$. the sum of the corresponding $\sigma_{\omega}{ }^{\mathrm{p}}$ values (correlation $\left.\mathrm{R}^{2}=0.97\right)$. The electrophilicities $E$ were obtained from reference 18 .

A good correlation is obtained between experimentally and theoretically derived electrophilicity parameters, showing that contributions by the latter are additive.

It is interesting to note that good linear correlations between Mayr's electrophilicity parameter $E$ and theoretical global electrophilicities $(\omega)$ for seven diarylcarbenium ions have been recently reported..$^{19}$ Correlation coefficients of $\mathrm{R}^{2}=0.95$ and 0.89 were obtained, when the theoretical electrophilicities were calculated with an HF or a B3LYP method, respectively.

This result is in apparent contradiction with the linear dependence of $E$ on $\sigma_{\omega}{ }^{p}$ for the same family of compounds, shown in Figure 6. In fact, if $E$ bears a linear relationship with $\omega$, then, according to equation $3, \log E$, and not $E$, should correlate linearly with $\sigma_{\omega}^{\mathrm{p}}$.
An explanation for this apparent contradiction lies on the fact that Chamorro et al. ${ }^{19}$ employed for their correlations a set of diarylcarbenium ions with strongly nucleophilic alkylamino substituents, and corresponding $E$ values in the range of -10.4 to -5.53 . Deviations from linearity in plots of $E v s$. $\omega$ should not be apparent when a small range of $E$ values is considered. In the case of Figure 6, a wider range of experimental electrophilicities were employed, from -7.02 to +6.02 . A good linear correlation in this case, with a range of substituents that include, besides the strongly nucleophilic $\mathrm{NMe}_{2}$, other less nucleophilic (OMe, Me) and even a slightly electrophilic substituent $(\mathrm{Cl})$, validates equation 3 and its extension to experimental data.

\section{Correlation with the oxidation potential of an organometallic complex}

A final example from a rather different type of process is the electrochemical oxidation of $\mathrm{Rh}(\mathrm{III})$ to $\mathrm{Rh}(\mathrm{IV})$ in the complexes below, where the nature of substituent $\mathrm{R}$ was expected to affect this potential, through the coordinated benzaldimine ligand..$^{20}$ Figure 7 is a plot of the oxidation potential of $\mathrm{Rh}(\mathrm{III})$ to $\mathrm{Rh}(\mathrm{IV})$ vs. $\sigma_{\omega}{ }^{\mathrm{p}}$ values for five derivatives, which included, besides the unsubstituted parent compound, nucleophilic (OMe, Me) and electrophilic $(\mathrm{Cl}$, $\mathrm{NO}_{2}$ ) substituents. The obtained $\rho_{\omega}$ value of 0.76 indicates that the ease of metal oxidation decreases with the increased electrophilicity of the R substituent.

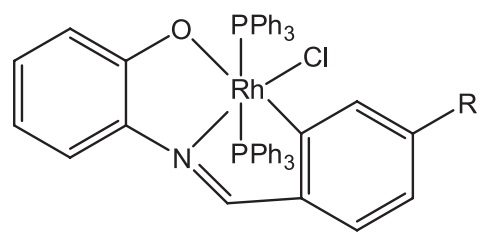

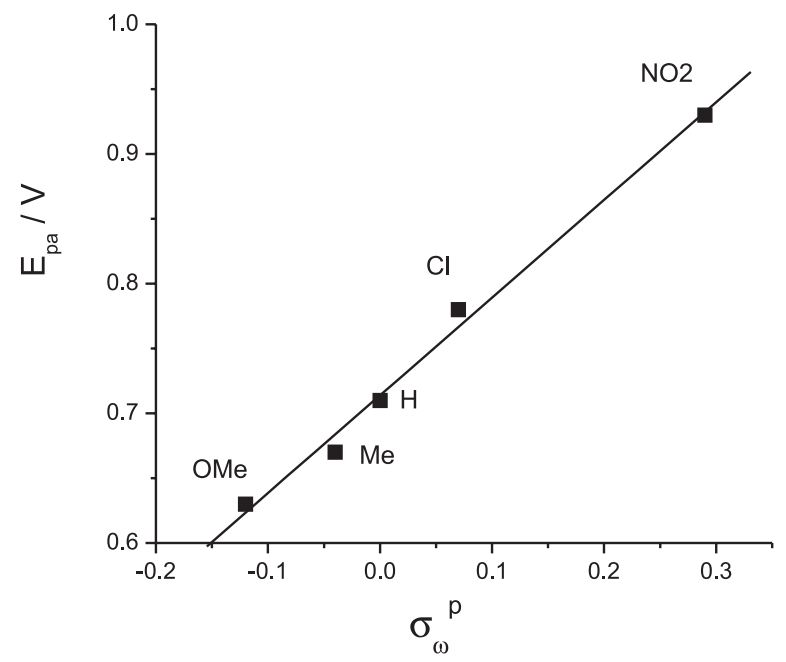

Figure 7. Plot of the oxidation potential of $\mathrm{Rh}$ (III) to $\mathrm{Rh}$ (IV) in a substituted benzaldimine complex vs. the electrophilic $\sigma_{\omega}{ }^{\mathrm{p}}$ value of substituents $\mathrm{R}$ (correlation $\mathrm{R}^{2}=0.99$ ). Experimental data were obtained from reference 20 . 
The above examples suffice to demonstrate the wide scope of equation 3 and the use of the electrophilic $\sigma_{\omega}$ constants derived from it.

Finally, the question is to ask ourselves how far the parallel behavior of Hammett's $\sigma$ and the electrophilic $\sigma_{\omega}$ constants go.

\section{Correlation with Hammett's $\sigma$ constants}

Figure 8 is a plot of the former $v s$. the latter constants, for the 46 substituents listed in Table 1. It is seen that the correlation between the two sets is rather good $\left(R^{2}=0.88\right)$, if only uncharged substituents are considered. The charged substituents $\left(\mathrm{Me}_{3} \mathrm{P}^{+}, \mathrm{Me}_{3} \mathrm{~N}^{+}, \mathrm{Me}_{2} \mathrm{~S}^{+}\right)$constitute a subset for which electrophilicities are overestimated, if compared with their corresponding Hammett's $\sigma$ values. This observation reinforces the remarks made above for the plot of Figure 5, and the anomalous behavior of the data points corresponding to the charged $\mathrm{Me}_{3} \mathrm{~N}^{+}$group.

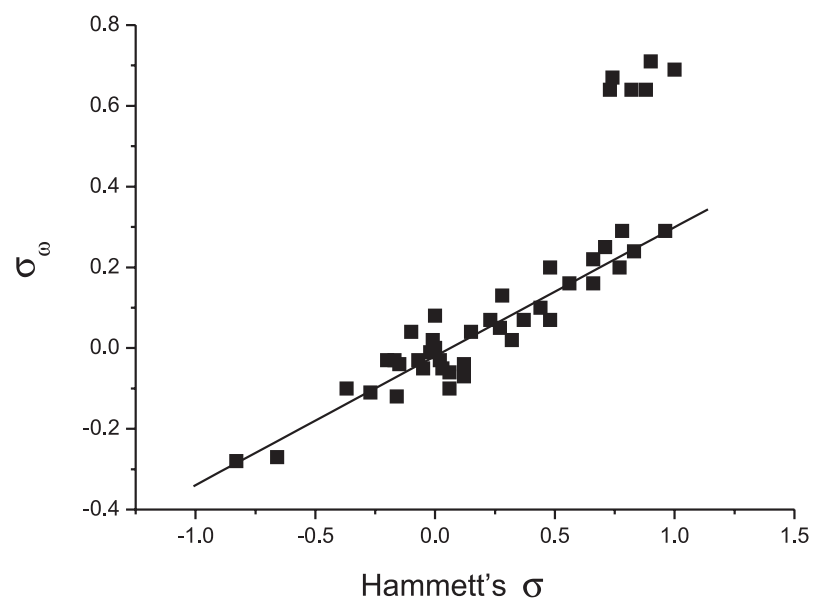

Figure 8. Plot of electrophilic $\sigma_{\omega} v s$. Hammett's $\sigma$ constants for all meta- and para-substituents of Table 1 (correlation $\mathrm{R}^{2}=0.88$ ). The points above the straight line correspond to positively charged substituents $\left(\mathrm{Me}_{3} \mathrm{~N}^{+}, \mathrm{Me}_{3} \mathrm{P}^{+}, \mathrm{Me}_{2} \mathrm{~S}^{+}\right)$

In view of the good correlation between Hammett's $\sigma$ and our theoretical $\sigma_{\omega}$ values, the linear plots shown in Figures 3-7 should not be a surprise. The poorer correlation between $\sigma_{\omega}$ and the pKa values of phenols (Figure 5) reflects the known failure of Hammett's $\sigma$ constants to reproduce the exalted conjugation between $\pi$-accepting substituents and the phenoxide charge. In this sense, the good correlation between $E$ and $\Sigma \sigma_{\omega}$ of Figure 6 is a bit surprising, because of the failure of $\sigma$ values to describe through-conjugation in arylcarbenium ions. A possible explanation for this may be the fact that the vast majority of the data points in Figure 6 correspond to strong electrondonating substituents, thus covering a rather limited range of $\sigma_{\omega}$ values.

An intriguing point, however, is the fact that the set of theoretically-derived electrophilic constants $\sigma_{\omega}$ exhibit such a good correlation with the empirically obtained $\sigma$ values. But it is possible to stress the differences between the theoretical approach that led to the definition of electrophilic substituent constants and the empirical nature of the Hammett equation. The $\sigma_{\omega}$ constant reflects a group contribution to the global electrophilicity of a substituted benzoic acid. Nothing is said about the acid deprotonation or the stabilization of a particular center of the molecule. Nevertheless, the $\sigma_{\omega}$ constants of Table 1 not only reflect the electrophilicity of a particular substituent, but also its position relative to the carboxylic acid group: para- and meta-values for the same substituent are generally different.

A possible explanation for this may be sought in the original concept of the global electrophilicity of a molecule. Its electrophilicity index is associated with the energy gained by the molecule immersed in a sea of free electron gas, after an amount of charge flows from the sea to the system. ${ }^{21}$ In the case of substituted benzoic acids, this charge-transfer corresponds to the first step of the two-step hypothetical process depicted by Scheme 1 .

The whole process is a gas-phase dissociation of substituted benzoic acids, and its free-energy should well correlate with Hammett's $\sigma$. The second step is relatively insensitive to the nature of $\mathrm{X}$, as it is a homolytic loss of a hydrogen radical. In consequence, the effect of substituent $\mathrm{X}$ on the deprotonation is fully reflected in the first step of the process. Thus, the electrophilic $\sigma_{\omega}$ and Hammett's $\sigma$ constants well correlate because they are derived from similar processes, where negative charge is locally built on the carbonyl oxygen.

The Scheme 1 also helps to understand why positively charged substituents fall off the straight line of Figure 8. For<smiles>[X]c1ccc(C(=O)O)cc1</smiles>

Scheme 1. 
neutral substituents, the carboxylic carbon atom is the most electrophilic center of the molecule, and charge will flow to the system to generate a ketyl radical anion, as shown in the Scheme 1. For positively charged substituents this is no longer true, and charge will flow to the more electrophilic substituent, in a different reduction process to that shown in the Scheme 1. For these substituents, the electrophilic $\sigma_{\omega}$ and Hammett's $\sigma$ constants no longer refer to the same process, and do not correlate.

\section{Conclusions}

The above results showed that there is a Hammettlike relationship between the global and substituent electrophilicities for substituted ethylenes and benzoic acids. This relationship is quite general, and allows the definition of substituent electrophilic $\sigma_{\omega}$ constants. Such theoretically-derived constants may be used in the analysis of various systems, relating the contribution of substituent electrophilicities to a variety of chemical processes. In fact, good correlations have been obtained by various groups, between the global electrophilicities of a family of substituted compounds and some constant related with their reactivity. Examples include linear relationships involving global or group electrophilicities in a variety of processes, such as the reactivity of benzhydryl carbocations, ${ }^{19,22}$ in the Baeyer-Villiger reaction of aldehydes and ketones, ${ }^{23}$ in the hydride affinities of quinones ${ }^{24}$ in the reaction of aryl benzoates with cyanide, ${ }^{25}$ or of $\alpha, \beta$-unsaturated carbonyl compounds with glutathione. ${ }^{26}$ These examples only add to the ones presented in the present work. In all cases, however, the authors have arrived at particular relationships, failing to recognize that such cases are particular examples of a general behavior. Our purpose in this work was to emphasize the existence of this general Hammett-like behavior involving global and substituent electrophilicities. Like the Hammett equation, such a general relationship will very probably find applications in the future for an ever-increasing number of chemical processes.

Due to the existence of this general Hammett-like behavior, electrophilic $\sigma_{\omega}$ values of uncharged substituents in general correlate well with normal Hammett's $\sigma$ values. This observation has also been made by other authors, but in general no effort has been made to search for an explanation to it. We suggest that it follows from their derivation from similar chemical processes. When this does not happen, as is the case with positively charged substituents, much larger $\sigma_{\omega}$ values are obtained than what might be predicted from their Hammett's $\sigma$ values.

\section{Acknowledgements}

Support from Fondo Nacional de Desarrollo Científico y Tecnólogico (Fondecyt) (project 1100022) is gratefully acknowledged.

\section{References}

1. De Proft, F.; Langenaeker, W.; Geerlings, P.; J. Phys. Chem. 1993, 97, 1826

2. Kneissler, J.; Zhou, Zh.; Int. J. Quantum Chem. 1994, 49, 309.

3. Roy, R. K.; Choho, K.; De Proft, F.; Geerlings, P.; J. Phys. Org. Chem. 1999, 12, 503.

4. Domingo, L. R.; Pérez, P.; Contreras, R; J. Org. Chem. 2003, 68, 6060 .

5. Elango, M.; Parthasarathi, R.; Narayanan, G. K.; Sabeelullah, A. M. D.; Sarkar, U.; Venkatasubramanian, N. S.; Subramanian, V.; Chattaraj, P. K.; J. Chem. Sci. 2005, 117, 61.

6. Chattaraj,P.K.; Sarkar, U.; Roy, D. R.; Chem. Rev. 2006, 106, 2065.

7. Parthasarathi, R.; Padmanabhan, J.; Elango, M.; Chitra, K.; Subramanian, V.; Chattaraj, P. K.; J. Phys. Chem. A 2006, 110, 6540.

8. Gupta, K.; Giri, S.; Chattaraj, P. K.; New J. Chem. 2008, 32, 1945.

9. Frisch, M. J.; Trucks, G. W.; Schlegel, H. B.; Scuseria, G. E.; Robb, M. A.; Cheeseman, J. R.; Montgomery, Jr., J. A.; Vreven, T.; Kudin, K. N.; Burant, J. C.; Millam, J. M.; Iyengar, S. S.; Tomasi, J.; Barone, V.; Mennucci, B.; Cossi, M.; Scalmani, G.; Rega, N.; Petersson, G. A.; Nakatsuji, H.; Hada, M.; Ehara, M.; Toyota, K.; Fukuda, R.; Hasegawa, J.; Ishida, M.; Nakajima, T.; Honda, Y.; Cammi, R.; Pomelli, C.; Ochterski, J. W.; Ayala, P. Y.; Morokuma, K.; Voth, G. A.; Salvador, P.; Dannenberg, J. J.; Zakrzewski, V. G.; Dapprich, S.; Daniels, A. D.; Strain, M. C.; Farkas, O.; Malick,D. K; Rabuck, A. D.; Raghavachari, K.; Foresman, J. B.; Ortiz, J. V.; Cui, Q.; Baboul, A. G.; Clifford, S.; Cioslowski, J.; Stefanov, B. B.;. Liu, G.; Liashenko, A.; Piskorz, P.; Komaromi, I.; Martin, R. L.; Fox, D. J.; Keith, T.; Al-Laham, M. A.; Peng, C. Y.; Nanayakkara, A.; Challacombe, M.; Gill, P. M. W.; Johnson, B.; Chen, W.; Wong, M. W.; Gonzalez, C.; Pople, J. A.; Gaussian 03, Revision C.02, Gaussian, Inc., Wallingford, CT, 2004.

10. Parr, R. G.; Pearson, R. G.; J. Am. Chem. Soc. 1983, 105, 7512.

11. Hansch, C.; Leo, A.; Taft, R. W.; Chem. Rev. 1991, 91, 165

12. Güven, A.; Int. J. Mol. Sci. 2005, 6, 257.

13. Watson, C. T.; Cai, S.; Shokhirev, N. V.; Walker, F. A.; Inorg. Chem. 2005, 44, 7468.

14. Jaffé, H. H.; Doak, G. O.; J. Am. Chem. Soc. 1955, 77, 4441.

15. Gardner, J. N.; Katritzky, A. R.; J. Chem. Soc. 1957, 4375.

16. Serjeant, E. P.; Dempsey, B.; Ionisation Constants of Organic Acids in Aqueous Solution, IUPAC Chemical Series No. 23; Pergamon Press: Oxford, 1979. 
17. Mayr, H.; Patz, M.; Angew.Chem., Int. Ed. Engl. 1994, 33, 938.

18. Mayr, H.; Bug, T.; Gotta, M. F.; Hering, N.; Irrgang, B.; Janker, B.; Kempf, B.; Loos, R.; Ofial, A. R.; Remennikov, G.; Schimmel, H.; J. Am. Chem. Soc. 2001, 123, 9500.

19. Chamorro, E.; Duque-Noreña, M.; Pérez, P.; J. Mol. Struct. (THEOCHEM) 2009, 901, 145.

20. Basu, S.; Dutta, S.; Drew, M. G. B.; Bhattacharya, S.; J. Organomet. Chem. 2006, 691, 3581.

21. Parr, R. G.; Szentpály, L. V.; Liu, S.; J. Am. Chem. Soc. 1999, 121, 1922.

22. Campodónico, P. R.; Pérez, C.; Aliaga, M.; Gazitúa, M.; Contreras, R.; Chem. Phys. Lett. 2007, 447, 375.
23. Meneses, L.; Araya, A.; Pilaquinga, F.; Fuentealba, P.; Chem. Phys. Letters 2008, 460, 27.

24. Campodónico, P. R.; Aizman, A.; Contreras, R.; Chem. Phys. Lett. 2009, 471, 168.

25. Campodónico, P. R.; Ormazábal-Toledo, R.; Aizman, A.; Contreras, R.; Chem. Phys. Lett. 2010, 498, 221.

26. Wondrousch, D.; Böhme, A.; Thaens, D.; Ost, N.; Schüürmann, G.; J. Phys. Chem. Lett. 2010, 1, 1605.

Submitted: March 4, 2011

Published online: September 1, 2011 